\title{
Análise da disponibilidade hídrica superficial na bacia hidrográfica do rio Piracicaba
}

\section{- MG}

\author{
Analysis of surface water availability in the watershed river Piracicaba - MG \\ Análisis de la disponibilidad de agua superficial en la cuenca hidrográfica Piracicaba - MG
}

\section{Resumo}

Diante da degradação dos recursos hídricos e sua indisponibilidade, torna-se necessário buscar medidas para promover o uso racional e propiciar recursos econômicos para a sua manutenção. A bacia hidrográfica do rio Piracicaba (MG), afluente do rio Doce, sofre uma forte pressão sobre os recursos hídricos, principalmente devido ao perfil econômico, com destaque para a mineração e a siderurgia. Logo, a determinação da disponibilidade hídrica da bacia fornece subsídios para a gestão integrada dos aspectos quantitativos dos recursos hídricos. Nesse sentido, o objetivo do trabalho foi determinar a disponibilidade hídrica superficial na bacia hidrográfica do rio Piracicaba. Para isso, a relação dos usuários de captação de água superficial foi obtida junto ao Instituto Mineiro de Gestão das Águas (Igam) e posteriormente analisada. Cálculos de disponibilidade hídrica trecho a trecho da bacia foram realizados, bem como o cálculo da viabilidade de regularização de vazão dos trechos com indisponibilidade hídrica. Como resultados, foram identificados 103 trechos com indisponibilidade hídrica na área de estudo, desses apenas 3 não possuem viabilidade de regularização de vazão. A informação de disponibilidade hídrica deve ser mantida atualizada periodicamente, a fim de obter um melhor cenário nas decisões do âmbito da gestão hídrica da bacia. Recomenda-se incluir a análise de captações subterrâneas junto às captações superficiais em estudos de disponibilidade hídrica de bacias hidrográficas.

Palavras-chave: Disponibilidade hídrica; Outorga; Rio Piracicaba; Vazões.

\begin{abstract}
In view of the degradation of hydric resources and their unavailability, it becomes necessary to seek measures to promote the rational use and provide economic resources for their maintenance. The watershed of the Piracicaba River (MG), a tributary of the Doce River, suffers strong pressure on its water resources, mainly due to its economic profile, with mining and steelworks standing out. Therefore, the determination of water availability in the basin provides subsidies for the integrated management of the quantitative aspects of water resources. In this sense, the objective of this study was to determine the surface water availability in the Piracicaba river basin. For this, the list of surface water users was obtained from the Instituto Mineiro de Gestão das Águas (Igam) and later analyzed. Calculations of water availability were carried out stretch by stretch of the basin, as well as the calculation of the viability of regulating the flow of the stretches with water unavailability. As a result, 103 sections with unavailable water were identified in the study area, of these only 3 have no feasibility of flow regulation. The information on water availability should be periodically updated, in order to obtain a better scenario for the decisions of the basin's water management. It is recommended to include an analysis of underground abstractions with surface abstractions in studies of water availability in watershed.
\end{abstract}

Keywords: Flow rates; Grant; Piracicaba river; Water availability. 


\begin{abstract}
Resumen
Dada la degradación de los recursos hídricos y su indisponibilidad, es necesario buscar medidas que promuevan el uso racional y proporcionen recursos económicos para su mantenimiento. La cuenca del río Piracicaba (MG), afluente del río Doce, sufre una fuerte presión sobre los recursos hídricos, principalmente debido a su perfil económico, especialmente la minería y la siderurgia. Por lo tanto, la determinación de la disponibilidad de agua de la cuenca proporciona ayudas para la gestión integrada de los aspectos cuantitativos de los recursos hídricos. En este sentido, el objetivo de este estudio fue determinar la disponibilidad de agua superficial en la cuenca del río Piracicaba. Para ello, se obtuvo la lista de usuarios de aguas superficiales del Instituto Mineiro de Gestão das Águas (Igam) y se analizó posteriormente. Se han realizado cálculos de disponibilidad hídrica tramo a tramo de la cuenca, así como el cálculo de la viabilidad de regulación del caudal de los tramos con indisponibilidad hídrica. Como resultado, se identificaron 103 tramos con agua no disponible en la zona de estudio, de los cuales sólo 3 no tienen viabilidad de regulación de caudal. La información sobre la disponibilidad de agua debe actualizarse periódicamente para obtener un mejor escenario para las decisiones relativas a la gestión del agua en la cuenca. Se recomienda incluir el análisis de la extracción de aguas subterráneas junto con la extracción de aguas superficiales en los estudios de disponibilidad de agua en las cuencas hidrográficas.
\end{abstract}

Palabras clave: Caudales; Conceder; Disponibilidad de agua; Río Piracicaba.

\title{
1. Introdução
}

A água é um bem natural comum, necessária para o uso vital de qualquer ser vivo e representa o ser humano de forma cultural, em seus valores sociais, quanto a sobrevivência, o sustento e o desenvolvimento. O Brasil possui grande parte dos recursos hídricos viáveis para os usos existentes. Mesmo com essa abundância, nos últimos anos a preocupação com ouso inadequado, o desperdício e a poluição dos recursos hídricos, vem tomando grandes proporções.

A degradação dos recursos hídricos coloca em risco as gerações futuras pelo perigo de escassez, o que faz necessário buscar medidas para promover sua utilização racional e ainda propiciar recursos econômicos para a sua manutenção (Boff, 2015).

Em Minas Gerais, muitos municípios enfrentam um período de estiagem rigorosa, provocando a falta de água. Um fator que pode dificultar a manutenção da distribuição de água para a sociedade é a disponibilidade hídrica, afetada pela variabilidade climática, pelo desperdício e por problemas ambientais, gerando transtornos, impondo restrições ao desenvolvimento econômico, cultural e social de várias regiões (Silva, 2015).

A consciência dos limites dos recursos naturais, dos quais a água é um dos mais essenciais, tem feito com que se busque formas de promover uma gestão integrada, que exige compreensão profunda do ciclo hídrico e de todos os aspectos intervenientes, influenciados pela ação humana (Silva, 2015).

Entre os instrumentos para a gestão integrada das águas está a outorga de direito de uso de recursos hídricos, implementada pela Lei Federal no 9.433/1997 que instituiu a Política Nacional de Recursos Hídricos. Assim, passou a ser condicionada a disponibilidade hídrica, em que o direito de uso é concedido aos usuários mediante a concessão de outorgas (Brasil, 1997).

A outorga de direito de uso de recursos hídricos fornece ao poder público uma forma de controlar a vazão de água que está sendo captada, bem como a qualidade da água que está sendo utilizada pelos usuários. A outorga tem o propósito de minimizar os conflitos pelo uso da água, garantindo o direito de acesso, estabelecendo condições específicas para as captações e os lançamentos de efluentes (Collischonn \& Lopes, 2009).

A legislação prevê usos isentos de outorgas como as derivações, captações e lançamentos insignificantes e o uso de recursos hídricos para necessidades em pequenos núcleos populacionais no meio rural (Brasil, 1997).

Moreira, Andrade e Gonçalves (2020), analisaram a escassez hídrica na bacia hidrográfica do Rio Suaçui (MG), conforme a Deliberação Normativa n ${ }^{\circ}$ 49, de 25 de março de 2015, alterada pela Deliberação Normativa CERH-MG n ${ }^{\circ} 50$, de $^{2}$ 09 de outubro de 2015, que estabelece diretrizes e critérios gerais para a definição de Situação Crítica de Escassez Hídrica e 
Estado de Restrição de Uso de Recursos Hídricos Superficiais nas porções hidrográficas do Estado de Minas Gerais. O objetivo do trabalho foi analisar a eficácia da legislação como forma de garantir a prevenção ou mitigação dos danos provenientes da ocorrência de eventos hidrológicos adversos na bacia. Os resultados mostraram que não foi possível mensurar a vazão captada em nenhum dos usos outorgados e verificar se foram tomadas as medidas de restrições impostas, devido ao descumprimento da obrigatoriedade de instalação de equipamentos de medição de vazão o que dificulta a gestão dos recursos hídricos.

Segundo Silva (2015), a metodologia de alocação de água para outorgas mais utilizada no Brasil, desde 1990, baseia-se em vazões mínimas de referência com o estabelecimento de limites de utilização dessas vazões. Essas vazões mínimas de referência são caracterizadas por sua magnitude, duração e frequência de ocorrência, representando diretamente o potencial natural disponível para o consumo dos usuários, sendo eles, para o uso industrial, navegação, geração de energia e lançamento de efluentes (Rodrigues, 2004).

As vazões mínimas são geradas por vazões de alta permanência no tempo, ou por vazões mínimas associadas a probabilidade de ocorrência. Sendo assim, é a vazão disponível mesmo em períodos de estiagem, com baixa probabilidade de falha. Toda essa metodologia de simulação do comportamento dos corpos de água e da sua variação ao longo do tempo é descartada, devido se referir ao ambiente mais severo possível. No entanto, não proporciona a alocação de água nos períodos abundantes de água (Lisboa, 2014).

Entre as vazões mínimas comumente utilizadas pela legislação brasileira para fins de outorga está a $\mathrm{Q}_{7,10}$, que corresponde a vazão calculada por meio da média das vazões mínimas diárias, calculadas por sete dias consecutivos, com um período de retorno de 10 anos. As desvantagens que existem para essa referência de vazão, são quanto as limitações excessivas do uso dos recursos hídricos (Lanna, Pereira \& Silva, 1997).

No estado de Minas Gerais, a Resolução Conjunta SEMAD-Igam n 1.548, de 29 de março de 2012 define como referência para o cálculo da disponibilidade hídrica superficial a vazão $Q_{7,10}$ e estabeleceu que $50 \%$ dessa vazão é o limite máximo de captações e diluições que podem ser outorgadas, garantindo a jusante de cada derivação, fluxos residuais mínimos de 50\% da $\mathrm{Q}_{7,10}$. Para as regiões de escassez hídrica o limite máximo de captações de diluição é 30\% (Igam, 2012).

Essa variedade de critérios também considera os valores que se relacionam quanto aos usos de baixa vazão ou de pouca expressão, denominados de usos insignificantes. Em Minas Gerais a Deliberação CERH-MG nº 09/2004, definiu 1,0 L/s e $0,5 \mathrm{~L} / \mathrm{s}$, para as regiões de escassez hídrica no estado, sendo esses os limites máximos de vazões de pouca expressão (CERH, 2004).

Na verificação sobre os pedidos de outorga, a liberação depende da disponibilidade hídrica natural do manancial. De acordo com critérios baseados na vazão de referência, das propriedades de uso estabelecidas em planos de recursos hídricos e demais critérios (Igam, 2012).

Duarte e Miola (2016), avaliaram a quantidade de outorgas concedidas para o uso dos recursos hídricos e se a vazão de água existente atende à demanda referente às outorgas concedidas. O estudo foi realizado na microbacia do Ribeirão Paciência em Pará de Minas (MG), após os levantamentos em relação a disponibilidade hídrica da bacia, observou-se que a água disponível consegue manter o equilíbrio entre a oferta e demanda. Entretanto, o aumento populacional, o crescimento industrial e a escassez de investimentos ambientais fazem com que ocorra uma pressão sobre os recursos hídricos.

Marques et al. (2021) realizaram uma análise sobre uma área de conflitos pelos usos de recursos hídricos, na bacia hidrográfica do córrego dos Quatis (MG). Destaca que o trabalho foi embasado no documento de Análise de Conflito pelo Uso da Água (ACUA) no 01/2019. Os resultados obtidos pelo ACUA mostraram valores de déficit hídrico na relação demanda $x$ disponibilidade, principalmente devido a irrigação. Como solução do conflito foi elaborado o Termo de alocação de água para a outorga coletiva. 
Silva, Pires e Carvalho Neto (2015), estimaram índices de conflito pelo uso da água na gestão e no planejamento dos recursos hídricos da bacia do rio Paraopeba (MG). Foram analisados os valores de disponibilidade hídrica do local, os valores das vazões outorgadas e estimadas e constatou-se que, em $22,7 \%$ dos trechos analisados, o total das vazões outorgadas são superiores as permitidas, demonstrando assim uma possível situação de conflito pelo uso da água.

Moreira et al. (2012), propuseram dois índices para identificar conflitos pelo uso da água com base na análise das vazões outorgáveis e na disponibilidade hídrica. Os índices apresentados visaram fornecer subsídios às ações que prejudicam a gestão dos recursos hídricos e fornecer dados para um melhor planejamento. O estudo permitiu constatar que a bacia analisada, apesar de não possuir um número alto de outorgas, apresentam regiões de conflitos. Para a utilização dos índices propostos pelos autores é importante que os órgãos responsáveis pelo diagnóstico da disponibilidade hídrica tenham o comprometimento com a atualização dos dados utilizados.

Lisboa, Silva e Moreira (2019), desenvolveram um sistema para análise das outorgas de captação de água e diluição de efluentes na bacia do rio Piracicaba (MG). Constataram que os trechos mais críticos em relação a vazão passível de outorga, localizam-se próximos a foz do rio principal.

Diante do exposto, o objetivo do trabalho foi analisar a disponibilidade hídrica superficial na bacia hidrográfica do rio Piracicaba (MG).

A análise da disponibilidade hídrica, bem como o balanço entre oferta e demanda hídrica na bacia do rio Piracicaba é importante para fornecer subsídios para a gestão integrada dos aspectos quantitativos dos recursos hídricos.

\section{Metodologia}

Segundo Pereira et al. (2018), método é o caminho para se realizar alguma coisa e quando se tem o caminho, torna-se mais fácil realizar viagens sabendo onde se está e aonde se quer chegar e como fazê-lo. Os métodos qualitativos são aqueles nos quais é importante a interpretação por parte do pesquisador com suas opiniões sobre o fenômeno em estudo. O presente estudo voltou-se principalmente a abordagem qualitativa. Apesar de haver a comparação de dados numéricos, a interpretação dos mesmos é de caráter qualitativo. Ademais, não menos importante, foi necessária a pesquisa explicativa para identificar os fatores que determinam ou contribuem para a ocorrência dos fenômenos.

Quanto ao atendimento dos objetivos propostos, o trabalho tem característica de pesquisa descritiva, o que significa identificar e comparar, para descrever os fatos e fenômenos de determinada realidade. A pesquisa descritiva foi determinada pelo estabelecimento de relação entre variáveis, como a comparação entre demanda e disponibilidade hídrica.

O estudo foi embasado principalmente na coleta e sistematização de informações, originárias de documentos, que constituíram as fontes primárias, como também informações secundárias, como relatórios técnicos e tabelas. Para a coleta e análise de dados, lançou-se mão da pesquisa documental, bibliográfica e estudo de caso.

\section{1 Área de estudo}

A bacia hidrográfica do Rio Piracicaba (MG) caracteriza-se pelo alto impacto ambiental causado por empresas do setor minerário, siderúrgico e de celulose, além da alta densidade populacional. A bacia insere-se totalmente no território de Minas Gerais, ocupando uma área de $5.681 \mathrm{~km}^{2}$, pertencente à bacia hidrográfica do rio Doce. A população estimada é de 984.236 habitantes (Lisboa, 2014).

As nascentes do rio Piracicaba estão localizadas no município de Ouro Preto, nas proximidades da Serra do Caraça, a $1.680 \mathrm{~m}$ de altitude, e desloca-se em direção Leste, percorrendo $241 \mathrm{~km}$ até encontrar o rio Doce na cidade de Ipatinga, a uma altitude de $210 \mathrm{~m}$ (Lisboa, 2014). 
A área de estudo envolve 21 municípios mineiros, dos quais 17 possuem a sede dentro dos limites da unidade de planejamento (Figura 1).

Figura 1 - Localização dos municípios na bacia hidrográfica do rio Piracicaba.

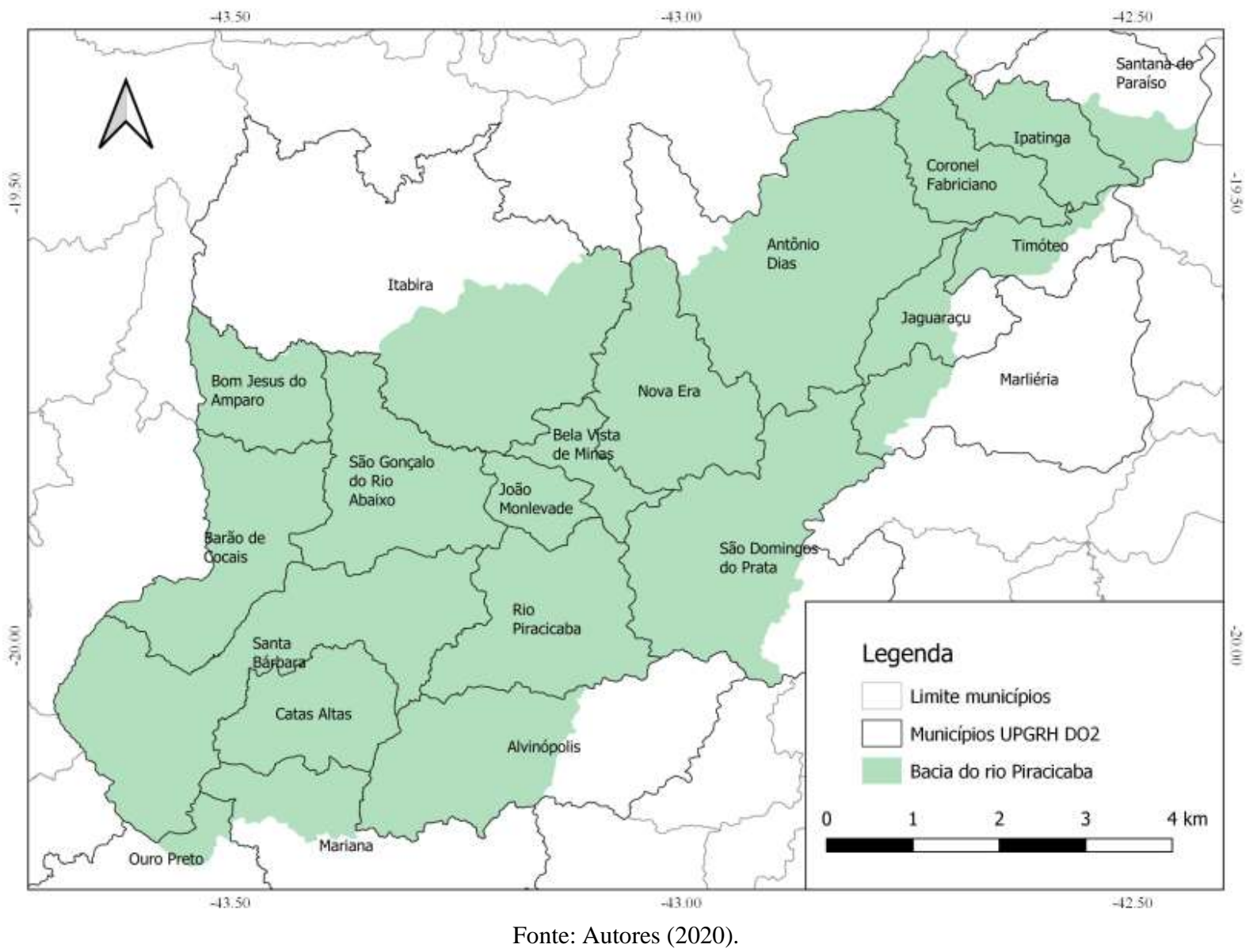

A bacia hidrográfica do rio Piracicaba é composta pelas sub-bacias do rio Santa Bárbara e do rio do Peixe, pela margem esquerda, e pela sub-bacia do rio da Prata, pela margem direita. As cidades de Barão de Cocais, Santa Bárbara e São Gonçalo do Rio Abaixo localizam-se às margens do rio Santa Bárbara, e São Domingos do Prata é cortada pelo rio da Prata. Ao longo do seu curso o rio Piracicaba recebe a descarga de quase uma centena de córregos e ribeirões, os quais compõem sua rede de drenagem (Consórcio Ecoplan - Lume, 2010).

A bacia do rio Piracicaba é uma região muito rica em recursos minerais, nela se encontra uma das maiores reservas do mundo em minério de ferro, manganês, bauxita, ouro, esmeralda, alumínio, quartzito entre outros. A geologia é composta pelo Quadrilátero Ferrífero e pelo Embasamento Cristalino (Consórcio Ecoplan - Lume, 2010).

\subsection{Cadastros dos usuários de água da bacia}

A metodologia escolhida para realização do presente estudo foi baseada no manual intitulado Metodologia para elaboração do Zoneamento Ambiental Produtivo, 2ª edição SEMAD/SEAPA-MG, 2016 (Faria et al., 2016).

Os dados dos usuários de captação de água superficial na área de abrangência da bacia hidrográfica do rio Piracicaba foram obtidos do Igam (Instituto Mineiro de Gestão das Águas), com informações do número do processo, coordenadas geográficas, portaria, ano da portaria, vazão de captação, curso d'água, finalidade, modelo de uso, tipo, data de publicação e validade. Foram excluídos das análises as captações subterrâneas. 
Selecionou-se as interferências considerando o status do processo como outorga deferida, renovada, retificada e cadastro efetivado (uso insignificante), excluindo os demais. Quanto a data de validade, foram considerados os processos a partir de seis meses antes da data de elaboração do estudo, ou seja, até dezembro de 2019.

Os usuários com modo de uso da água, como por exemplo, canalização/retificação de curso d'água, barramento em curso d'água sem captação, travessia rodoferroviária, dragagem, limpeza e desassoreamento de curso d'água, foram excluídos pois os mesmos não interferem na disponibilidade hídrica quantitativa.

$\mathrm{Na}$ análise de consistência dos dados, foram verificadas a ocorrência de processos repetidos e a vazão de captação de cada processo nas portarias de outorga por meio do sítio eletrônico da Secretaria de Estado de Meio Ambiente e Desenvolvimento Sustentável de Meio Ambiente (SEMAD), principalmente em relação à unidade de medida, para padronização em m³/s. Uma vez que há os dados de vazão para cada mês do ano, considerou-se o maior valor. Para os cadastros de uso insignificante - não possuem portaria - não foi possível conferir o valor correto, logo os valores de vazão foram arredondados para $1 \mathrm{~L} / \mathrm{s}$ (valor máximo).

Durante todo processamento de dados em relação ao mapeamento, utilizou-se o software livre QGIS versão 3.10. O sistema de referência de coordenadas do projeto no QGIS foi padronizado em todos os arquivos para SIRGAS 2000/ UTM zone 23S. Para melhor visualização e compreensão da demanda hídrica na bacia, foi gerado um mapa referente aos resultados do cadastro dos usuários de água.

\subsection{Análise da disponibilidade hídrica da bacia}

Para a análise da disponibilidade hídrica da bacia hidrográfica do rio Piracicaba foram utilizados os dados de vazão das outorgas e dos cadastros de uso insignificante, bem como a vazão $\mathrm{Q}_{7,10}$ da base do estudo de regionalização de vazão da Universidade Federal de Viçosa (UFV) e Igam disponibilizado no website do IDE-Sisema. Observa-se que na bacia do rio Piracicaba o limite máximo de captações a serem outorgadas, em condições naturais é de $50 \%$ da $\mathrm{Q}_{7,10}$.

Para o cálculo da vazão ainda passível de captação na bacia, considerou-se um ponto a jusante de todas as captações na bacia, com área de drenagem de $5.465 \mathrm{~km}^{2}$, localizado próximo à foz do rio Piracicaba.

A vazão disponível para novas captações (Qdisp_cap), m³/s, está representada pela Equação 1.

$$
\mathrm{Q}_{\text {disp_cap }}=\mathrm{xQ}_{\mathrm{mrs}}-\Sigma \mathrm{Q}_{\text {cap }}
$$

em que,

x: percentual da $\mathrm{Q}_{\mathrm{mr}}$ passível de ser outorgada, expressa em decimal, adimensional;

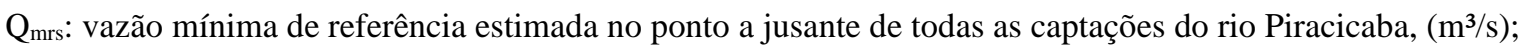

Qcap: vazão captada na bacia do rio Piracicaba, $\left(\mathrm{m}^{3} / \mathrm{s}\right)$.

Na bacia do rio Piracicaba o limite máximo para novas captações é de $50 \%$ da vazão mínima de referência $\left(\mathrm{Q}_{7,10}\right)$. Para a estimativa dessa vazão no ponto a jusante de todas as captações utilizou-se o modelo ajustado proposto pelo Atlas Digital das Águas de Minas, conforme Equação 2.

$$
\mathrm{Q}_{7,10}=0,0038 * \mathrm{~A}^{1,0129}
$$

em que:

A: área de drenagem à montante do ponto a jusante de todas as captações, $\left(\mathrm{km}^{2}\right)$.

A vazão de disponibilidade hídrica (QDH), m³/s, em cada trecho, foi calculada por meio da Equação 3. 


$$
\mathrm{Q}_{\mathrm{DH}}=\mathrm{xQ} \mathrm{mr}_{\mathrm{m}}-\mathrm{Q}_{\text {DemTotal }}
$$

em que:

Qmr: vazão mínima de referência estimada em cada trecho, $\left(\mathrm{m}^{3} / \mathrm{s}\right)$;

QDemTotal: vazão de demanda total em cada trecho, $\left(\mathrm{m}^{3} / \mathrm{s}\right)$.

A porcentagem de comprometimento da disponibilidade hídrica (compromDH) foi calculada por meio da equação seguinte.

$$
\text { compromDH }=\frac{\mathrm{xQ}_{\mathrm{mr}}-\mathrm{Q}_{\mathrm{DH}}}{\mathrm{xQ}_{\mathrm{mr}}} * 100
$$

Após esse procedimento, os trechos dos cursos d'água da bacia foram classificados de acordo com as situações de indisponibilidade (> 100\%), estado de atenção (50 a 100\%) e de disponibilidade $(<50 \%)$.

Para os trechos com indisponibilidade hídrica, a alternativa quanto ao incremento da regularização de vazão é uma forma de atender a demanda existente, com isso, foi calculado a viabilidade de regularização de vazão para cada trecho comprometido na bacia do rio Piracicaba.

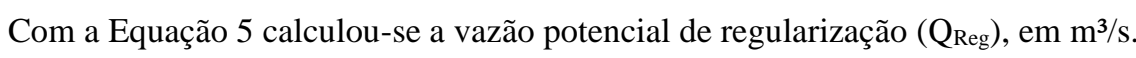

$$
\mathrm{Q}_{\mathrm{Reg}}=\left(0,7 * \mathrm{Q}_{\mathrm{mld}}\right)-\mathrm{x} \mathrm{Q}_{\mathrm{mr}}
$$

em que:

Qmld: vazão média de longa duração, $\left(\mathrm{m}^{3} / \mathrm{s}\right)$;

Para os trechos com indisponibilidade hídrica calculou-se a viabilidade de regularização de vazão (ViabRegQ), m³/s, utilizando a Equação 6.

$$
\text { ViabRegQ }=Q_{\text {Reg }}+Q_{D H}
$$

A construção de barragens para regularização de cheias pode ser uma alternativa para garantir a vazão necessária para atender as necessidades de uso da água no trecho do curso d'água em questão, quando a viabilidade de regularização de vazão for positiva. 


\section{Resultados e Discussão}

\subsection{Cadastro de usuários de uso da água}

Existem 534 cadastros de usos insignificantes e 134 pontos de outorga de uso da água, totalizando 668 captações superficiais na bacia hidrográfica do rio Piracicaba, com demanda de $8,13 \mathrm{~m} / \mathrm{s}$. Desse total, $68 \%$ corresponde a apenas cinco empreendimentos, localizados nos municípios de Ipatinga, João Monlevade, Ouro Preto, São Gonçalo do Rio Abaixo e Timóteo. Os usuários estão apresentados na Figura 2.

Figura 2 - Captações superficiais em corpo de água na bacia do rio Piracicaba.

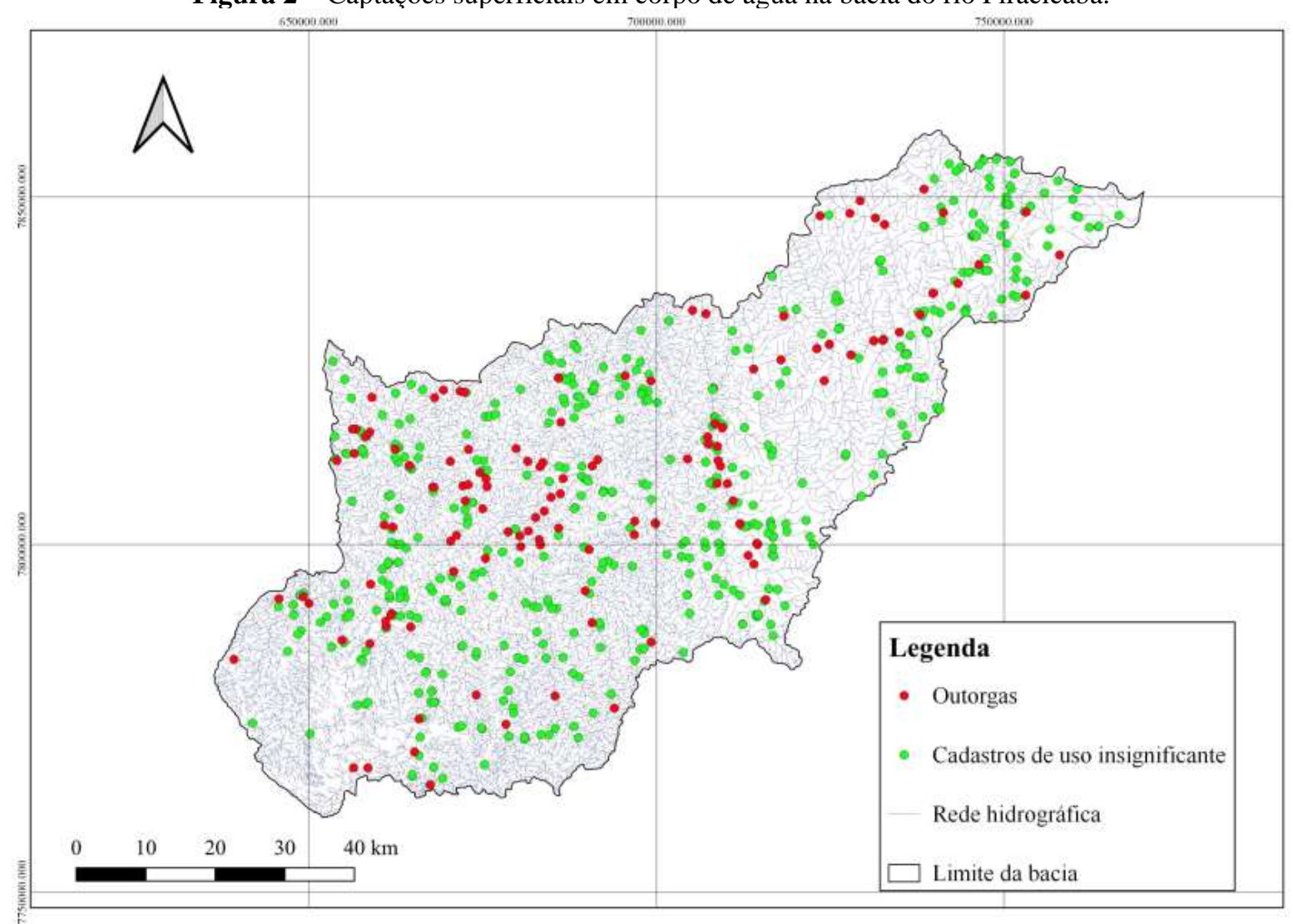

Fonte: Autores (2020).

Na bacia do rio Piracicaba é predominante o abastecimento industrial, representado pelas indústrias de mineração, siderurgia, entre outras, que possuem uma com vazão demandada de $6,48 \mathrm{~m} 3 / \mathrm{s}$. O consumo humano é o segundo maior uso consuntivo, correspondendo a vazão de $0,89 \mathrm{~m}^{3} / \mathrm{s}$, seguindo pela aspersão em vias $\left(0,38 \mathrm{~m}^{3} / \mathrm{s}\right)$.

Em porcentagem, o consumo industrial corresponde por $80 \%$ do uso hídrico na bacia, o consumo humano $11 \%$ e a aspersão em vias corresponde a 5\% das retiradas. Os demais usos como irrigação, aquicultura, obras civis de rodovias e dessedentação animal são pouco expressivos na bacia, sendo que cada um corresponde por aproximadamente $1 \%$ das retiradas.

Os valores de demanda industrial são elevados, principalmente junto aos municípios mais industrializados da região metropolitana do Vale do Aço. Acrescidas as demandas urbanas, a bacia do rio Piracicaba destaca-se pela característica urbano-industrial da região.

É importante ressaltar que as vazões médias efetivas tendem a ser inferiores, especialmente para grandes usuários, visto que o valor outorgado tende a um limite máximo de abastecimento, a exemplo de uma indústria operando com $100 \%$ da capacidade instalada ou de um município que visa atender sua crescente população em um horizonte futuro. Dessa forma, 
pode-se dizer que o inventário de cadastros e outorgas de uso da água não garantem precisão quanto as vazões efetivamente utilizadas.

\subsection{Quantidade de água e vazão passível de captação}

Quanto a vazão passível de captação no rio Piracicaba, observa-se que a $\mathrm{Q}_{7,10}$ no ponto a jusante de todas as captações da bacia é de $23,21 \mathrm{~m} 3 / \mathrm{s}$, para área de drenagem correspondente a 5.465,69 $\mathrm{km}^{2}$. Dessa forma, a disponibilidade hídrica máxima passível de captação é de $11,61 \mathrm{~m} / \mathrm{s}$. Verifica-se que a soma das captações na bacia é de $8,13 \mathrm{~m} / \mathrm{s}$, assim a vazão disponível para novas captações superficiais é igual a 3,48 m³/s, ou seja, houve redução de $70 \%$ do limite máximo.

Portanto, considerando a disponibilidade hídrica total da bacia, verificou-se que o balanço entre oferta e demanda hídrica é positivo.

\subsection{Análise da disponibilidade hídrica da bacia do rio Piracicaba}

A bacia hidrográfica do rio Piracicaba é composta de 18.498 trechos de cursos d'água, os quais foram identificados com um ottocódigo. Dos 18.498 trechos, 523 apresentam demanda pelo uso de recursos hídricos. Pode-se dizer que os trechos com demanda hídrica estão pulverizados por toda a bacia. A Figura 3 apresenta a localização desses trechos na bacia.

Figura 3 - Localização dos trechos com demanda hídrica na bacia.

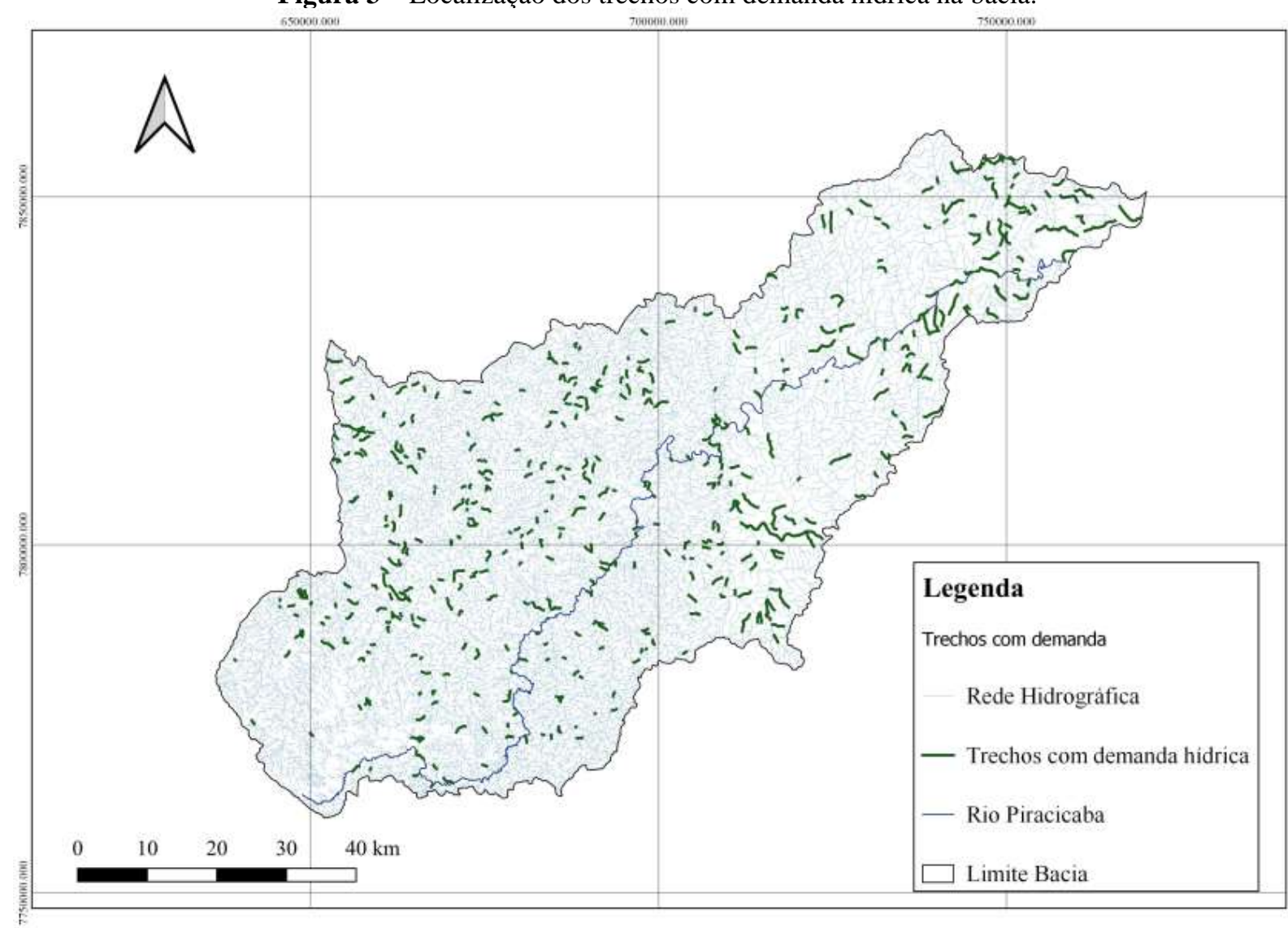

Fonte: Autores (2020).

Quanto a disponibilidade hídrica em cada trecho, verificou-se que a bacia do rio Piracicaba possui 103 trechos de indisponibilidade, ou seja, comprometimento hídrico maior que 100\% da vazão mínima de referência e 93 trechos em estado de atenção comprometimento entre 50 e 100\% da vazão mínima de referência. A figura a seguir apresenta a localização desses trechos. 
Figura 4 - Disponibilidade hídrica na bacia do rio Piracicaba.

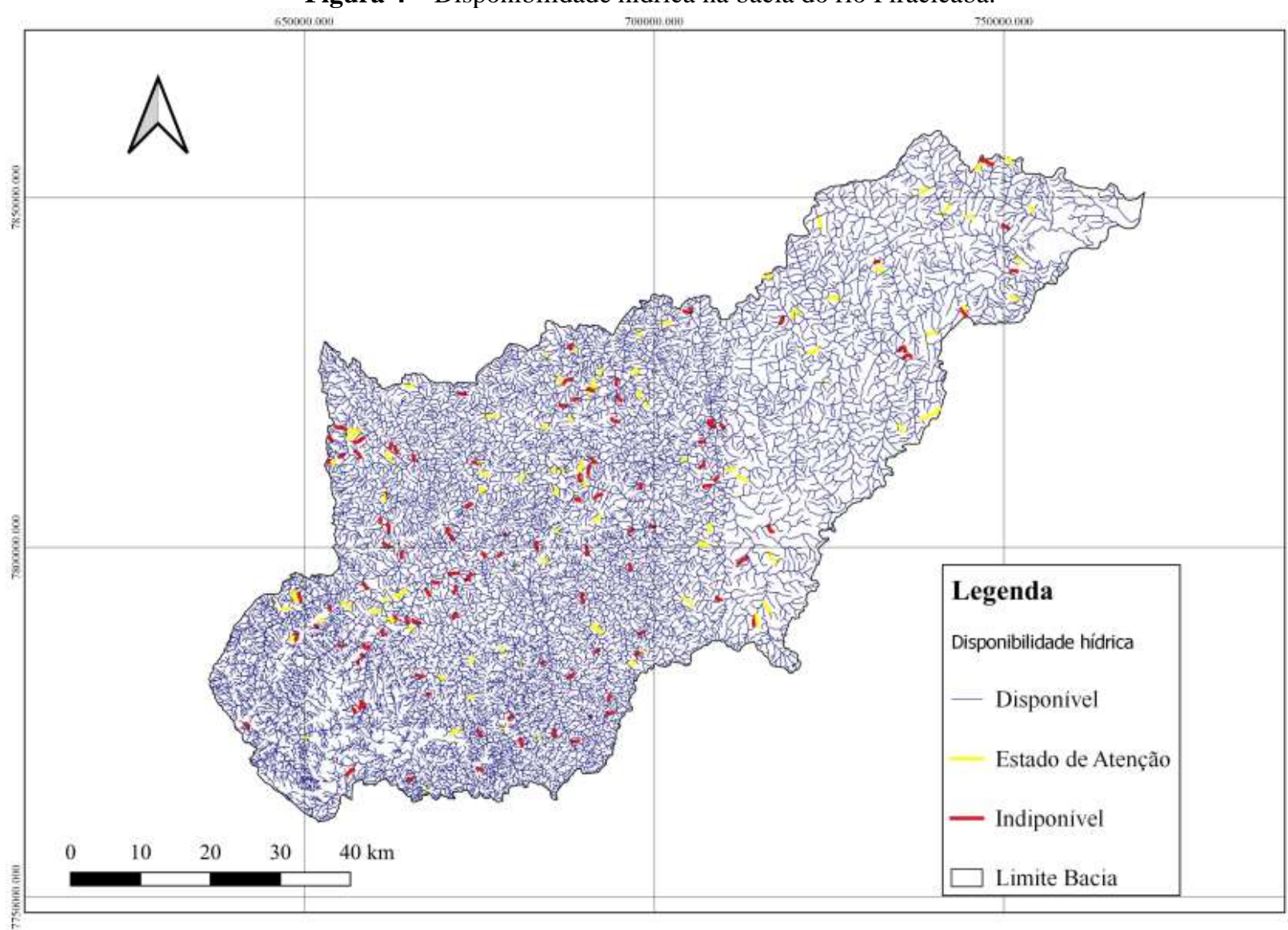

Fonte: Autores (2020).

Os trechos representados por "Estado de Atenção" e "Indisponível" se encontram espalhados ao longo da bacia em áreas mais a montante do rio do Piracicaba, em trechos de primeira e segunda ordem.

Observou-se que os cadastros de usos insignificantes são os principais responsáveis pelos trechos de indisponibilidade hídrica da bacia; os mesmos não requerem avaliação técnica do órgão ambiental, desde que o volume solicitado não ultrapasse $1 \mathrm{~L} / \mathrm{s}$.

A distribuição por município dos trechos com indisponibilidade hídrica na bacia hidrográfica do rio Piracicaba mostra que os municípios de Santa Bárbara e Barão de Cocais apresentam maiores números de trechos com indisponibilidade, sendo 19 e 12 trechos, respectivamente.

\subsection{Regularização de vazão}

A regularização de vazão é essencial quando a demanda de água é maior que a vazão mínima. Isso torna necessária a acumulação dos excessos para atender períodos cuja disponibilidade hídrica natural é menor que a demanda de captação. (Oliveira et al., 2020).

Dos 103 trechos com indisponibilidade hídrica da bacia, 100 deles possuem viabilidade de regularização de vazão por meio de barramentos. No entanto, deve ser levada em consideração a viabilidade ambiental, econômica e social desse tipo de estrutura.

Além da construção de barramentos para os trechos com indisponibilidade hídrica, existem outras alternativas para o incremento de vazão nas sub-bacias hidrográficas, como por exemplo, melhorar a gestão por meio de análise de todos os 
usuários existentes, bem como das novas captações de água na bacia, revitalizar e investimentos na bacia hidrográfica por meio de projetos e programas que melhorem a quantidade de água nos pontos de escassez.

Apenas 3 trechos, em destaque na Figura 5, não possuem viabilidade de regularização de vazão por meio de barramentos.

Figura 5 - Viabilidade de regularização de vazão.

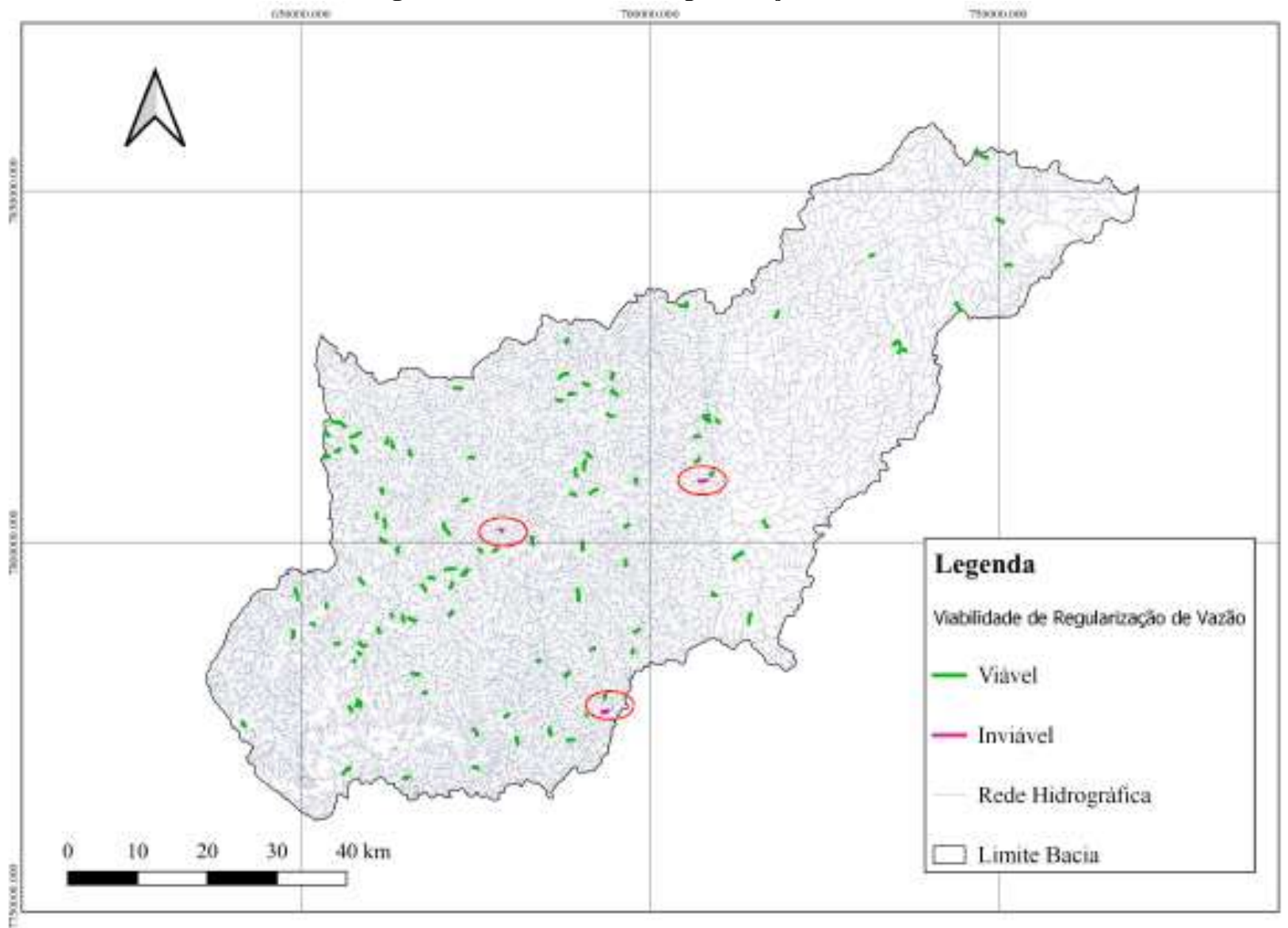

Fonte: Autores (2020).

Os trechos destacados com círculo na Figura 5 possuem vazão de captação de água elevada em relação a disponibilidade hídrica da sub-bacia hidrográfica. Percebe-se que a área de drenagem da sub-bacia hidrográfica desses trechos com escassez são pequenas, não produzindo quantidade de água necessária para regularizar a vazão, por meio da construção de pequenos barramentos, de acordo com a metodologia adotada.

Dos 3 trechos com inviabilidade regularização de vazão, o primeiro trecho possui cinco captações de uso insignificante, os outros dois trechos dispõem de outorgas de vazões elevadas para a área de drenagem da sub-bacia. Com isso, nesses trechos a construção de barragem de regularização de vazão não é suficiente para regularizar a vazão do curso d'água.

\section{Considerações Finais}

As captações de água não impactam na disponibilidade hídrica da bacia, considerando a disponibilidade total. Dessa forma, a vazão de água disponível na bacia do rio Piracicaba é suficiente para manter positiva a relação entre oferta e demanda de água. 
Neste trabalho, buscou-se metodologicamente mapear trechos com indisponibilidade hídrica na bacia hidrográfica do rio Piracicaba, a fim de disponibilizar aos órgãos gestores de recursos hídricos um instrumento de análise e planejamento. A identificação de trechos altamente pressionados pelas captações de água, está diretamente ligada ao sistema de gerenciamento de recursos hídricos tanto nos aspectos ambientais quanto nos aspectos sociais, uma vez que os projetos e programas que melhorem a quantidade de água podem ser priorizados nas bacias com escassez.

Foram identificados 103 trechos com indisponibilidade hídrica na bacia hidrográfica do rio Piracicaba, desses apenas 3 trechos não possuem viabilidade de regularização de vazão por meio de pequenos barramentos. No entanto, deve ser levada em consideração a viabilidade ambiental, econômica e social desse tipo de estrutura.

Existe a necessidade de avaliação da evolução temporal da situação da disponibilidade hídrica, no sentido de se conhecer como a disponibilidade hídrica se comporta no tempo e no espaço estudado. Com a atualização deste mapeamento será possível uma constante avaliação das captações superficiais de água na bacia, através da comparação entre os mapas elaborados. Tal prática demonstra-se indispensável para a eficácia da gestão ambiental na área de estudo. Dessa forma, o produto de disponibilidade hídrica deve se manter atualizado no intuito de obter um melhor cenário nas decisões do âmbito da gestão hídrica da bacia do rio Piracicaba.

A metodologia proposta considerou o estudo de regionalização de vazões da UFV e Igam na bacia do rio Piracicaba, trazendo contribuições significativas para os estudos ambientais. Pode-se dizer que a metodologia usada neste estudo se comprovou eficaz, pois foi possível determinar a disponibilidade hídrica para toda bacia.

Por fim, o estudo de disponibilidade hídrica é um instrumento de diagnóstico e acompanhamento para gestão da bacia e tomada de decisões. A partir daí, ações devem ser implementadas visando a manutenção e recuperação das bacias com a finalidade de prevenir conflitos pelo uso da água ou uma possível crise hídrica.

Recomenda-se, como sugestão a trabalhos futuros, incluir a análise de captações subterrâneas junto as captações superficiais em estudos de disponibilidade hídrica de bacias hidrográficas.

\section{Agradecimentos}

Ao Programa de Mestrado Profissional em Rede Nacional em Gestão e Regulação de Recursos Hídricos PROFÁGUA, Projeto CAPES/ANA AUXPE No. 2717/2015, pelo apoio técnico científico.

\section{Referências}

Brasil. (1997). Lei Federal $n^{\circ}$ 9.433, de 8 de janeiro de 1997. Institui a Política Nacional de Recursos Hídricos, cria o Sistema Nacional de Gerenciamento de Recursos Hídricos, regulamenta o inciso XIX do art. 21 da Constituição Federal, e altera o art. $1^{\circ}$ da Lei ${ }^{\circ} 8.001$.

Boff, L. (2015). A água no mundo e sua escassez no Brasil. https://leonardoboff.wordpress.com/2015/02/02/a-agua-no-mundo-e-sua-escasseznobrasil/.

Collischonn, B. \& Lopes, A. V. (2009). Sistema de apoio à decisão para análise de outorga na bacia do rio Paraná. In Anais do 18 Simpósio Brasileiro de Recursos Hídricos. Campo Grande. https://www.abrhidro.org.br/SGCv3/publicacao.php?PUB=3\&ID=110\&SUM

$\mathrm{ARIO}=2044$

CERH - Conselho Estadual de Recursos Hídricos. (2004). Deliberação Normativa CERH - MG $n^{\circ} 09$, de 16 de junho de 2004. Define os usos insignificantes para as circunscrições hidrográficas no Estado de Minas Gerais.

Consórcio Ecoplan - Lume. (2010). Plano de Ação de Recursos Hídricos da Unidade de Planejamento e Gestão dos Recursos Hídricos Piracicaba. http://www.cbhdoce.org.br/wp-content/uploads/2015/01/PARH_Piracicaba.pdf.

Duarte, V. A. \& Miola, D. T. B. (2016). Análise de disponibilidade hídrica na microbacia do Ribeirão Paciência: relação entre a oferta e o volume de água outorgado em Pará de Minas. Revista Digital FAPAM. 7 (7), 32-54.

Igam - Instituto Mineiro de Gestão das Águas. (2012). Resolução Conjunta SEMAD-Igam no 1548, de 29 de março 2012 . Dispõe sobre a vazão de referência para o cálculo da disponibilidade hídrica superficial nas bacias hidrográficas do Estado de Minas Gerais.

Faria, L.V, Brito, G. C. B., Cagna, C. E. \& Leão, G. O. (2016). Metodologia do Zoneamento Ambiental Produtivo - ZAP de sub-bacias hidrográfica. Ed 2a, Belo Horizonte - MG, 2016. 
Research, Society and Development, v. 10, n. 3, e42610313552, 2021

(CC BY 4.0) | ISSN 2525-3409 | DOI: http://dx.doi.org/10.33448/rsd-v10i3.13552

Lanna, A. E., Pereira, J. S. \& Silva, L. M. (1997). Análise de critérios de outorga de direito de uso da água. In Anais do 12 Simpósio Brasileiro de Recursos Hídricos. Vitória.

Lisboa, L. (2014). Sistema para análise das outorgas de captação de água e diluição de efluentes na bacia do rio Piranga-MG. Tese de doutorado, Universidade Federal de Viçosa, Viçosa, MG, Brasil.

Lisboa, L., Silva, D. D. \& Moreira, M. C. (2019). Sistema para análise das outorgas de captação de água e diluição de efluentes na bacia do rio Piranga (MG). Revista de Engenharia Sanitária e Ambiental. 24(5), 929-937. https://www.scielo.br/pdf/esa/v24n5/1809-4457-esa-24-05-929.pdf.

Marques, H. F. M., Reis, B. C., Feitoza, V. S., Silva, J. G \& Monte-Mor, R. C. A. (2021). Conflitos na gestão de recursos hídricos no Estado de Minas Gerais: Estudo de caso da Bacia Hidrográfica do córrego dos Quatis, Itueta - Minas Gerais, Brasil. Research, Society and Development, 10 (1), e27910111967. http://dx.doi.org/10.33448/rsd-v10i1.11967.

Moreira, G. B., Andrade, C. B. S., \& Gonçalves, J. A. C. (2020). A fiscalização do uso outorgado dos recursos hídricos de bacia declarada em situação crítica de escassez hídrica: estudo de caso na bacia Rio Suaçui - MG. Research, Society and Development, 9 (7), e81973729. http://dx.doi.org/10.33448/rsdv9i7.3729.

Moreira, M. C., Silva, D. D., Pruski, F. F. \& Lara, M. S. (2012). Índices para identificação de conflitos pelo uso da água: proposição metodológica e estudos de caso. Revista Brasileira de Recursos Hídricos. 1 (3), 7-15.

Oliveira, J. P. A., Uliana, E. M., Mendes, M. A. S. A. \& Lisboa, L. (2020). Regionalização da curva de regularização de vazão da bacia do rio Juruena. Research, Society and Development, 9 (10), e2539108637. http://dx.doi.org/10.33448/rsd-v9i10.8637.

Pereira A. S. et al. (2018). Metodologia da pesquisa científica. https://repositorio.ufsm.br/bitstream/handle/1/15824/Lic_Computacao_Metodologia-PesquisaCientifica.pdf?sequence $=1$.

Rodrigues, R. G. (2004). Metodologia para estimativa das demandas e das disponibilidades hídricas na bacia do rio Paracatu. Dissertação de mestrado, Universidade Federal de Viçosa, Viçosa, MG, Brasil.

Silva, B. M. (2015). Índices para a gestão e planejamento de recursos hídricos na bacia do rio Paraopeba, Estado de Minas Gerais. Revista Ambiente \& Água. $10(3), 685-697$

Silva, L. L. B., Pires, D. F. \& Carvalho Neto, S. (2015). Desenvolvimento de Aplicações para Dispositivos Móveis: Tipos e Exemplo de Aplicação na plataforma iOS. In II Workshop de Iniciação Científica em Sistemas de Informação. Goiânia. 